Housing Studies

\title{
Housing aspirations, pathways, and provision: contradictions and compromises in pursuit of voluntary simplicity
}

\section{Marisa McArthur \& Elaine Stratford}

To cite this article: Marisa McArthur \& Elaine Stratford (2020): Housing aspirations, pathways, and provision: contradictions and compromises in pursuit of voluntary simplicity, Housing Studies, DOI: 10.1080/02673037.2020.1720614

To link to this article: https://doi.org/10.1080/02673037.2020.1720614

曲 Published online: 06 Feb 2020.

Submit your article to this journal $\widetilde{x}$

Џ Article views: 14

Q View related articles $₫$

View Crossmark data $₫$ 


\title{
Housing aspirations, pathways, and provision: contradictions and compromises in pursuit of voluntary simplicity
}

\author{
Marisa McArthur and Elaine Stratford \\ Discipline of Geography and Spatial Sciences, School of Technology, Environments and Design, \\ University of Tasmania, Hobart, Australia
}

\begin{abstract}
Housing is a caring act prompting individuals and groups to challenge the contours of housing policies and systems as they pursue housing aspirations, shape housing pathways, and secure housing provision. In this article, we think critically about housing as part of an infrastructure of care and about how housing aspirations, pathways, and provisioning inform moral and caring acts known as voluntary simplicity. We focus on housing aspirations, pathways, and provisioning to document how those three 'rub up' against four specific provision processes (preparation, purchase, design, and permissions and implementation) and conclude that voluntary simplicity could be a powerful tool by which to shape more caring housing futures - if it was troubled by fewer contradictions and compromises in its application and if those subscribing to it were supported by a few key resources. Findings point to general and widespread opportunities to think more about the relationship of voluntary simplicity to housing studies, including in small-scale studies in regional centres.
\end{abstract}

\section{ARTICLE HISTORY}

Received 24 October 2018

Accepted 21 January 2020

\section{KEYWORDS}

Housing aspirations; housing pathways; housing provision; households; voluntary simplicity; Tasmania; Australia

\section{Introduction}

In this article, our aim is to critically examine relationships between housing and voluntary simplicity that are important to delineate and timely to consider in housing studies. We advance that aim by engaging with ideas about housing aspirations (Preece et al., 2020), housing pathways (Clapham, 2002, 2005), and infrastructures of care (Power \& Mee, 2019). That engagement is augmented by our reference to an empirical study in which we worked with members of a social group in Tasmania, Australia. To such ends, we consider how those people dealt with contradictions and compromises that challenged their aspirations for and commitments to voluntary simplicity in housing. As the larger literature shows, their experiences have salience for those wanting to better understand how housing shapes and is shaped by certain ontological frameworks, voluntary simplicity being one such example. 
The first of two premises from which we work is that housing provision is a moral act involving choices that inform cycles of production and consumption fundamental to individual and collective well-being and social participation. Thus, housing is also part of a moral economy (Alexander et al., 2018) and an infrastructure of care (Power \& Mee, 2019), affecting the contours of the political economy and associated policy settings. Consider distinctions between housing systems and markets, and failures to focus on the former's general malaise. Consider housing's relationship to socio-demographic changes such as ageing and pension systems ill-suited to managing housing costs in retirement; or credit crunches, rising un- and underemployment, in-work poverty, economic insecurity, and price inflation above wage increases; or rising house prices, falling rates of homeownership, housing supply shortages, and ongoing stereotypes about housing and associated and partial solutions to housing crises (Opit et al., 2020; Schifferes \& Shafique, 2018). Consider, too, the ways in which housing both contributes to and mitigates the effects of ecological degradation (Bhatti, 1993; Brown \& Bhatti, 2003; Pickerill, 2017).

The size and severity of the aforesaid predicaments mean that individual change in pursuit of societal 'good' may be minimally effective until scaled up; yet, such change is pragmatically and symbolically important. Little wonder individuals and social groups feel compelled to act on their values and push against consumer cultures shaped by deep-seated, intransigent beliefs. For some, voluntary simplicity is a viable alternative to consumer culture and stands in contrast to precarity - doing less with less and less (Elgin, 2010; Evans, 2011; Standing, 2011).

Voluntary simplicity is a 'mindful approach to consumption ... to meet basic material needs as ... sustainably as possible and [direct] time and energy away from limitless material pursuits in favour of exploring 'the good life' in non-materialistic sources of meaning and fulfilment' (Read et al., 2018, np; see also Alexander, 2012a, and Alexander, 2012b, on degrowth per se, and Rees, 2010, on unsustainability). Thus, our second premise is that - where choice is lacking or limited and in lieu of shared visions - individuals and social groups find ways to act, for example by challenging and shaping the contours of effective housing policies and systems. Notwithstanding this capacity to act, those engaged in voluntary simplicity appear to find it socio-emotionally, economically, and spatially complex. Doing better with less requires a range of resources, capacities, and practices neither easily internalized nor lived. We may aspire to simplicity and want to live in such ways yet be unable to marshal the wherewithal to do so, or we may be unable to exercise such choice because of structural and systemic impediments.

In light of the premises sketched above, in what follows we consider two propositions. First, we suggest that the relationship between voluntary simplicity and housing is under-examined and worth addressing - both intrinsically and for what it can contribute to wider debates. We elaborate on such matters in the next section, which outlines the theoretical framework and context, and which refers to a select literature on housing and voluntary simplicity, including in Australia and Tasmania.

Second, we suggest a modest empirical case study may help address gaps in understanding about people's aspirations, pathways, and choices when dealing with housing provision processes and prompt more work on such matters. This suggestion seems 
important given 'lack of clarity and conceptual specificity about ... [and] a limited empirical evidence base exploring how such aspirations may be changing within the fundamental reconfiguration of contemporary housing systems' (Preece et al., 2020, p. 87).

After explaining the methods used for the case study, we consider these empirical insights by analysing findings from in-depth interviews with 39 Tasmanians and exploring their aspirations for voluntary simplicity and associated housing provision choices (see also Field, 2015). We note the appeal made by Preece et al. (2020) for more empirical work on relationships between aspirations and the conditions needed to change housing systems, of which provisioning is a part. Thus, we focus on four key housing provision processes emphasized by our participants: preparation, purchase, design, and permissions and implementation. Those processes shaped their lives, sometimes for weeks and years, as they dealt with contradictions in housing production and consumption practices and market systems and learned to enact voluntary simplicity. We also examine how provision processes influenced participants' choices to compromise housing aspirations and values or handled self-doubt about whether their local actions would influence larger ethical and ontological debates about how to live a good and caring life (Wright, 2013).

By way of conclusion, we then consider how voluntary simplicity could be a compelling response to contemporary (housing) challenges if ready access were available to time, financial resources, expertise, healthy places, and appropriate materials. By reference to the trials involved in making sustainable housing choices in a modest-sized, socially isolated, and economically and ecologically complex market Tasmania - our first hope is that the paper contributes theoretical insights to, and helps advance growing empirical understandings about, housing aspirations and pathways and ecologically motivated moral choices oriented to producing voluntarily simple infrastructures of care. Our second hope is that the work aligns with and augments the small number of works at the interface of housing studies and studies of voluntary simplicity.

\section{Theoretical framework and context}

Our first suggestion is to propose that the relationship between voluntary simplicity and housing is under-examined and worth addressing, both intrinsically and for what it can contribute to wider debates.

\section{Initial insights from databases and the literature}

Voluntary simplicity is most often associated with environmentalism, and much less often linked to discussions about housing. Considering scholarship in the five years from 2015, and starting by reference to Housing Studies itself, from a total of 12 papers the last overt engagement with voluntary simplicity was in 2015, with only two papers and a book review on 'environmentally sustainable housing' appearing between 2009 and 2013. Many references to 'sustainable housing' exist in the journal's pages but a tendency to conflate viability with sustainability dilutes debate about 
Table 1. Indicative numbers of papers related to voluntary simplicity and housing.

\begin{tabular}{lcc}
\hline Database & \multicolumn{2}{c}{ Google Scholar } \\
\hline Search term | count & Overall & Since 2015 \\
'voluntary simplicity' and 'housing' & 2490 & 684 \\
'voluntary simplicity' and 'housing studies' & 49 & 14 \\
'voluntary simplicity' and 'housing consumption' & 33 & 3 \\
'voluntary simplicity' and 'housing provision' & 28 & 7 \\
'voluntary simplicity' and 'housing choice' & 27 & 5 \\
'voluntary simplicity' and 'housing preference' & 3 & 0 \\
'voluntary simplicity' and 'housing pathways' & 2 & 2 \\
Database & Scopus & \\
Search term | count & Overall & 50 \\
'voluntary simplicity' and 'housing' & 106 & 7 \\
'voluntary simplicity' and 'housing studies' & 10 & 0 \\
'voluntary simplicity' and 'housing consumption' & 4 & 0 \\
'voluntary simplicity' and 'housing provision' & 0 & 0 \\
'voluntary simplicity' and 'housing choice' & 0 & 0 \\
'voluntary simplicity' and 'housing preference' & 1 & 0 \\
'voluntary simplicity' and 'housing pathways' & 0 &
\end{tabular}

ecological sustainability as originally conceived during the decades following 1992 (Brown \& Bhatti, 2003).

Casting the net wider than the journal, Google Scholar lists 19 systematic literature reviews since 2015 indirectly to 'voluntary simplicity' and/or 'housing', but there seems to be no review directly on this subject. An additional scan of both Google Scholar and the Scopus search engines suggests there is limited work specifically linking voluntary simplicity and housing. Table 1 summarizes the numbers of papers published at any time under certain keywords. Its purpose is to show the volume and spread of work, but it does not signal any systematic approach on our part since a review of the literature using PRISMA or other systematic protocols was beyond the scope of the study.

Instead, what interests us is the fact that 'behind' these keywords are more detailed engagements with (a) frugality, sufficiency economics, downsizing, and shifting spatial norms; (b) motives for subscribing to voluntary simplicity and the effects of doing so; (c) learning from intentional communities about voluntary simplicity, democracy, and nonviolence; (d) measuring low-consumption lifestyles; (e) asking how voluntary simplicity is informed by utilitarianism, Kantian deontology, and virtue ethics; ( $f$ ) considering the contributions of voluntary simplicity to housing resilience in the face of climate change effects; voluntary simplicity and energy policy, including off-grid living; (g) micro-dwellings; (h) voluntary simplicity in different tenure types; autonomous architecture; and (i) considering new ways to think about home in low impact societies. Some works account for intersectionality and the influences of Indigeneity, race, gender, sexuality, cultural difference, vulnerable families, precarity, and disability.

In other words, thinking about voluntary simplicity and housing requires breadth, but also points to the need for more focused considerations, and we hope that this article prompts such efforts more generally.

\section{Ways to theorize the emergent relationship between voluntary simplicity and housing}

Our own thinking on the relationship between voluntary simplicity and housing is inductive and proceeds by synthesizing what we learned from our empirical studies 
and the literature. The framework that emerges is based on an understanding that housing pathways and choices have ontological, epistemic, structural, and agentic influences and effects. Our reflections go something like this:

Householders' values, aspirations, prior experiences, and preferences shape and are shaped by those same pathways and choices and housing provision processes. Outputs [dwellings] and outcomes [ways of dwelling] arising from the pathways taken and the choices exercised are necessarily contradictory and compromised: this is the tension between the ideal and the real and, howsoever experienced, it informs new pathways and choices.

Considering the component parts in Figure 1, it will be apparent that thinking about values and aspirations is important for us, and in a review of empirical research studies, Preece et al. (2020) provide timely insights in this respect. Their argument is that housing aspirations are 'desires to achieve housing-related ambitions in the future, encapsulating optimistic assessments of what can be realized' (p. 90), and shape how housing systems function across political, economic, social, and cultural domains. Notwithstanding, they call for more conceptual clarity about how aspirations are understood and for more empirical evidence 'exploring how such aspirations

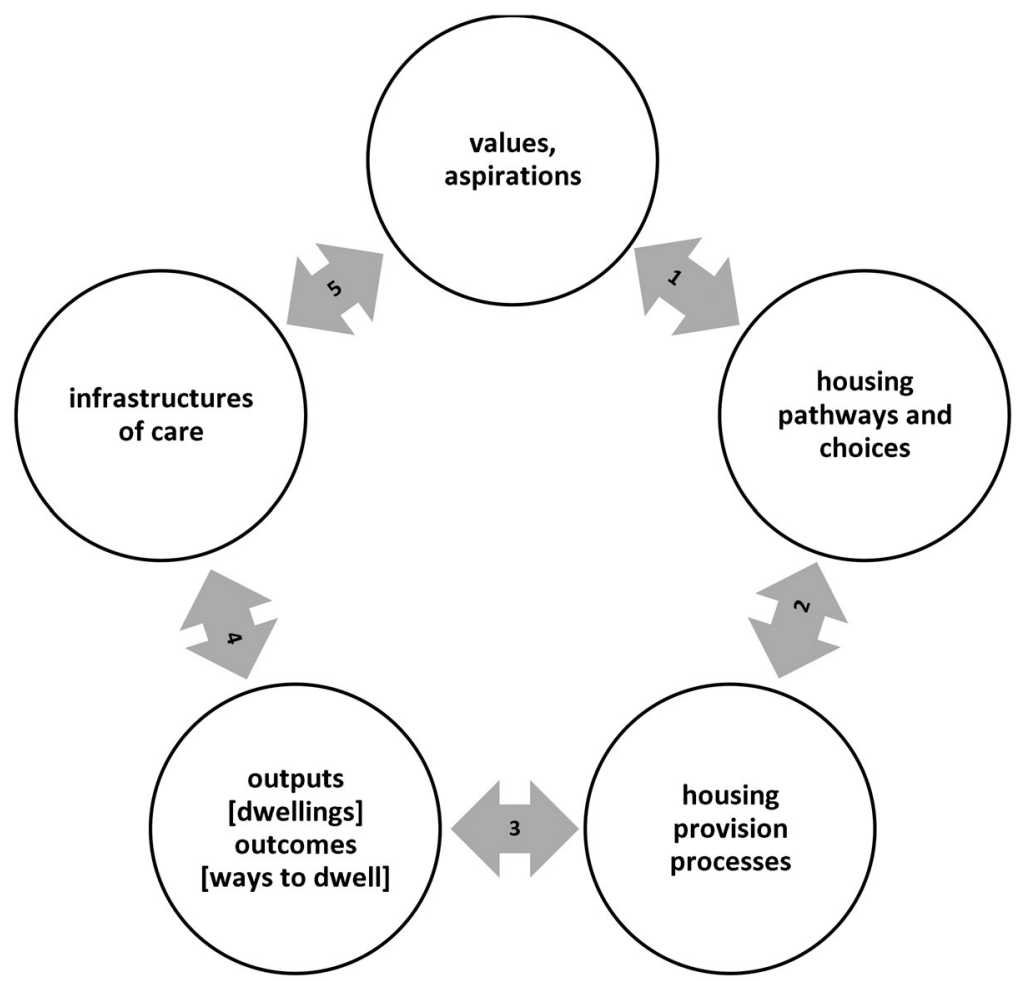

Figure 1. Cycles of aspiration, pathways, choices, and outputs and outcomes.

Notes

1. Householder opts to try and live in voluntary simplicity and ideal pathway preferences are chosen.

2. Various realities shape housing provision processes in householder's locale.

3. Housing provision's outputs and outcomes partly contradict initial aspirations and involve compromise.

4. People feel more or less comfortable or uncomfortable with the results.

5. Affective and cognitive insights arise from experiences and shape approaches to housing and its provision in the future. 
may be changing within the fundamental reconfiguration of contemporary housing systems' (p. 87). They also ask for multidimensional understandings of aspiration and want it decoupled from a choice framework. For them, while there are links between housing aspirations and choices, the relationship is not a necessary one: those 'not planning or engaged in a move of home still have housing aspirations, as do those with little choice' (p. 88). We acknowledge the importance of this insight; while our own work is concerned with householders who have made the choice to advance their aspirations and work through the trade-offs that arose, we appreciate that 'the relationship between socialized, subjective preferences and the wider structural possibilities for their realization is central to understanding housing aspirations' (p. 96).

For us, and as Figure 1 also shows, it is important to think about housing pathways and choices: 'the household forms in which individuals participate and the routes they take over time in their experience of housing' (Clapham, 2005, p. 2). Hence the utility of Clapham's (2002) insights on dynamics giving effect, on the one hand, to identity and lifestyle formation and performance and, on the other, to housing pathways and provision choices and the power relations that inform them. Hence, too, the ongoing relevance of Clapham's call, in the same work, for approaches that place 'households at the centre of the analysis' (p. 61). Either way, there is a significant literature on how the housing pathways approach reveals 'patterns of interaction (practices) concerning house and home, over time and space' and involves different 'social practices as well as ... more widely recognised physical changes' and accounting for the influence of 'other types of pathway such as employment' and of people's propensity for life planning (Clapham, 2002, pp. 63-65).

Given our assertion that affective and cognitive insights arise from experiences and shape approaches to housing and its provision in the future (Figure 1, point 5), it seems important to ask - as one of our referees did - whose approaches might be shaped? The individuals involved? Others who were not directly involved? If the latter, how will this knowledge transfer occur? Addressing those questions is outside the scope of the paper, but we think that there potentially intriguing connections between them and this idea of life planning. Often, little in the way of support for such ends is provided in formal settings such as families and schools, but there are diverse and learned skills that can make major life-course decisions less fraught. In our findings, below, three emerge: management capacities, risk appetite, and financial savvy.

\section{Voluntary simplicity as an infrastructure of care?}

Beyond the aforesaid considerations about voluntary simplicity and housing per se, it is useful to think about their relationship to certain infrastructures of care. These infrastructures are more-or-less enabled by values and aspirations and by housing pathways and choices that materialize via certain provision processes; lead to certain outputs and outcomes; and are filtered by levels of cognitive and affective dissonance with these results (hence the order of the parts in Figure 1).

Timely in relation to infrastructures of care is work by Power \& Mee (2019), including their examination of the contributions of housing to care - of which voluntary simplicity is, we think, a part. They call for analyses that focus on questions such 
as 'how does housing pattern the organization and practice of care across scales?' (p. 3). This question resonates for us because among our participants, housing provision processes are co-constituted by commitments to voluntary simplicity and involve (power) relations outside the household at scales larger than the dwelling or block. As Power and Mee emphasize, it is important to 'consider the operation of care in the broader housing system ... [which] opens a substantively new direction in housing scholarship, identifying housing as a sociomaterial assemblage that is constitutive of care' (p. 3). Some such care is clearly directed by householders to the morethan-human world and, for some, it manifests in lifestyle and housing choices and commitments to voluntary simplicity.

Enticing here is an observation by Power and Mee that 'there has been little detailed consideration of how housing shapes care practice' (p. 3), and that invites ontological and epistemological labours about 'world making' (p. 5). Voluntary simplicity is a practical philosophy - one such way to make the world - involving life choices to reduce resource consumption, improve ecological and social outcomes and quality of life, secure personal fulfilment, and exercise social responsibility (Black \& Cherrier, 2010; Kollmus \& Agyeman, 2002; McGinnis et al., 2013; Sandlin \& Walther, 2009; Zamwel et al., 2014). The logic is that when people consume less, and do so locally and mindfully, commensurate systems of production and disposal adjust, and people and systems flourish in contexts that promote degrowth (Alexander, 2012a).

Several comparable descriptions of voluntary simplicity exist. For Gregg (1936, p. 2), adherents to this value system have 'singleness of purpose, sincerity and honesty' and - foreshadowing the declutter movement - and avoid possessions that distract and detract from the 'deliberate organisation of life' for higher ends. His account runs close to Alexander's (2011, p. 186), which posits voluntary simplicity as an 'oppositional living strategy that rejects the high consumption, materialistic lifestyles of consumer cultures and affirms ... "the simple life" or "downshifting". In turn, Elgin (1981, p. 92) suggests voluntary simplicity involves living 'more consciously' with a 'minimum of distraction' to secure a life 'outward simple, inwardly rich', mindful it is processual and laborious. Leonard-Barton (1981, p. 244) writes of voluntary simplicity as one's capacity to secure a lifestyle to 'maximize ... direct control over daily activities and to minimize ... consumption and dependency' (see also Chhetri et al., 2009). Etzioni (1998, p. 620) describes it as a choice based in free will to limit engagement in consumer society and 'cultivate non-materialistic sources of satisfaction and meaning' (see Alexander \& Ussher, 2012; McDonald et al., 2006). Craig-Lees \& Hill (2002, p. 191) emphasize the point that such a stance assumes significant privilege as well as 'control and personal fulfilment' and experiences that favour attachment to 'humanism, self-determination, environmentalism, spirituality, and self-development'.

Common across accounts is the insight that voluntary simplicity is normative and ontogenetic - concerned with how things ought to be and with how they become. Voluntary simplicity requires political commitment to forms of conduct and practice. Understood thus, it informs housing provision processes. So, for example, appropriate designs and ethically sourced materials can be expensive - sometimes prohibitively and require difficult degrees of compromise from a normative ideal. Living in urban 
centres to reduce transport impacts can mean higher rents or mortgage repayments and entanglement in banking systems. Paying less for housing in hinterland, rural, and disadvantaged areas may increase car use and complicate access support networks, services, and amenities. Choices there may be, but they require compromises to preference hierarchies, and involve contradictions over social, economic, and environmental values, beliefs, and practices.

\section{Context for this study}

In Australia, access to fossil fuels, advanced technologies and synthetic materials, and finance have allowed and encouraged many people to build and buy beyond basic needs (McGee, 2013). Much of the period after 1945 is characterized by economic security, social stability, and technological advancement and typified by increasing rates of homeownership, at least until the 2016 Census of Population and Housing (Stone et al., 2017). Shifts in urban planning practice and institutional and financial support for state and private housing schemes have enabled the spread of low-density suburbs, increased car dependence, the separation of work from home, and growing evidence of conspicuous consumption and marked poverty. Many such processes have been highly profitable (Gleeson, 2006; Gurran, 2011) and influenced neoliberal and post-political philosophies and practices (Legacy et al., 2018). Growth agendas, vested interests, and private property rights have overshadowed social housing, environmentally stringent measures in housing construction, or innovative forms of housing tenure (see Crabtree, 2018; Gurran et al., 2009; Steele, 2009). In the process, planning has sometimes seemed increasingly de-democratized and distant from housing policy objectives related to need, choice, or affordability (Gurran, 2011; MacDonald, 2018). Developers, builders, and homeowners seem to work at cross-purposes and produce sub-optimal outcomes for housing, communities, and environments; homelessness and housing precarity have grown (Crabtree \& Hes, 2009; Greenop, 2017).

Our study on voluntary simplicity and housing choice and their contradictions and compromises is based in Tasmania. This state has distinctive geographies, development patterns based on the exploitation of natural resources, insular social values (Stratford, 2006a, 2006b, 2008), and personal and community histories steeped in connections to land and wilderness (Reynolds, 2012).

Not surprisingly, Tasmania has been also 'the location of embryonic experiments in community and economic development and ecological management' (Stratford, 2003, p. 496). Mindful of these dynamics, we worked in south-eastern local government areas (LGAs) near and including the capital, Hobart. The regional population's environmental values and relaxed culture make the locale a desirable place for many to live, despite limited employment opportunities and deep disadvantage in several locales more pronounced than in comparable regional settings in mainland Australia (Eslake, 2016).

Wages and salaries and house and land prices that are lower than the national average, and old housing stock tend to affect housing provision in Tasmania, although national residential property prices between the March quarters for 2018 and 2019 reveal a current counter-trend (Australian Bureau of Statistics, 2019b; Table 2). 
Table 2. Residential property prices, Australia.

\begin{tabular}{lcc}
\hline & $\begin{array}{c}\text { December quarter } 2018 \text { to March } \\
\text { quarter } 2019 \text { (\% change) }\end{array}$ & $\begin{array}{c}\text { March quarter } 2018 \text { to March } \\
\text { quarter } 2019 \text { (\% change) }\end{array}$ \\
\hline Weighted average & -3.0 & -7.4 \\
Sydney & -3.9 & -10.3 \\
Melbourne & -3.8 & -9.4 \\
Brisbane & -1.5 & -1.3 \\
Adelaide & -0.2 & 0.8 \\
Perth & -1.1 & -2.7 \\
Hobart & -0.4 & 4.6 \\
Darwin & -1.8 & -4.2 \\
Canberra & -0.9 & 0.0
\end{tabular}

Source: Australian Bureau of Statistics (2019a, 2019b).

Such change may be unprecedented and complicates housing provision choices in multiple ways related to simplicity, as well as to precarity and affordability (Eccleston et al., 2018a, 2018b).

Other differences exist between the state and national trends. In 2003-2004, the average cost to build a new house in the most expensive housing state, New South Wales, was $\$ 210,300$ and in Tasmania, it was $\$ 150,300$. In 2017-2018, those figures had changed to $\$ 348,400$ and $\$ 291,500$, respectively, but the largest proportional increase was, in fact, in Tasmania and occurred between 2003-2004 and 2010-2011, 11.3\% compared to New South Wales's 6.6\% (Australian Bureau of Statistics, 2019a).

Nationally, the average floor area of a new house expanded from $162.2 \mathrm{~m}^{2}$ in 1984-1985 to $247.7 \mathrm{~m}^{2}$ in 2008-2009, an increase of $52.7 \%$ (Australian Bureau of Statistics, 2005, 2013). Although the average floor area of new houses has declined (to $231.9 \mathrm{~m}^{2}$ in 2017-2018), Australians still build some of the largest detached dwellings in the world, second only to the United States (CommSec, 2017). At $188.3 .0 \mathrm{~m}^{2}$ in 2017-2018, the Tasmanian average is the lowest of all the states, and that has been consistent since at least 2003-2004 (Australian Bureau of Statistics, 2019a).

Australians tend to be highly mobile, with $58.3 \%$ of the population moving to a new dwelling in the five years prior to the 2011 census, and $56.6 \%$ in the five years prior to the 2016 census. Reflecting such movement patterns, Tasmania's population has also grown - mostly from in-migration - and has risen from 476,481 people in 2006 to 509,965 in 2016 (Australian Bureau of Statistics, 2017a), and at time of writing is circa 522,327. Although Tasmanians were least likely of all Australian states' residents to have changed address in the five years leading up to the 2016 census, over a third of the population - 37.8\% - did so (Australian Bureau of Statistics, 2011, 2017b).

Finally, in Tasmania, as elsewhere in Australia, increasing urbanization and innercity gentrification have encouraged some to move to suburbs on city fringes where vacant land has been more abundant and detached single dwellings have been the norm. Meanwhile, settlements are increasingly spatially and ideologically distant from hinterlands that provide food, water, waste disposal, resources, and goods (Gleeson, 2006, 2015; Rees, 2012). As Moore et al. (2016) note, sustainable housing stock is not being provided, and progress is reflected in disjointedly incremental changes to building performance, codes, and policies. 


\section{Methods of approach}

Thus far, we have asserted the need for more work on the relationship between housing studies and practices and voluntary simplicity. We are galvanized by calls from Power \& Mee (2019, p. 17) for housing and other scholars to 'speculate on possibilities for more caring housing markets, or to questions of housing governance, asking how housing might be better governed to support a flourishing of human life and domestic care'. We are also buttressed by arguments advanced by Brown \& Bhatti (2003, p. 511) that the 'environment can become an essential part of tackling poverty, improving health, and promoting social inclusion' and foster innovations in environmental housing among consumers, urban planners and policy-makers, and developers. And we recall that Preece et al. (2020) have asked for more in the way of empirical research on housing aspirations; surely a part of that involves aspiring to voluntary simplicity outcomes achieved by changes in housing provision processes.

Our study suited qualitative methods sensitive to how 'the social world is interpreted, understood, experienced, produced or constituted' (Mason, 2002, p. 4). Qualitative research fostered rich, detailed descriptions and comparisons from a small number of participants' accounts so we could delve more deeply into each (McGinnis et al., 2013, p. 72; Stratford \& Bradshaw, 2016). Electing to use in-depth interviews, we secured ethics clearance to speak with participants: residents who self-identify or whom others identified as subscribing to voluntary simplicity and who sought to apply those principles in practice in housing provision choices. They had wide-ranging life experiences, and chose to settle, build, and dwell in Tasmania - some because it is also a place known as a seedbed of the green political movement (Timms, 2009).

We recruited all 39 participants using a combination of criterion and snowball selection methods. Starting from one individual known to us because of their commitment to voluntary simplicity in housing, we then sought people who lived in houses that included at least one among the following combinations: off-grid; on-grid; built from alternative, recycled, prefabricated, or eco-materials; rammed earth; straw bale; retrofitted; yurt; rented, owned, and/or communal/strata title; and rural, suburban, and urban.

At varying stages in the life course, participants ranged in age from their early 20 s to late 70s, occupied several housing types, held many worldviews, and included single people, couples, and families (Kemeny, 1992). It is noteworthy that 25 participants were engaged in work associated with housing: architecture, building design and construction, energy efficiency consulting, masonry, landscaping, drafting, planning, local government, surveying, and sustainability. Their knowledge intersected with their housing provision choices, and choices they helped others' shape. They chose the locations for their interviews, sometimes opting to highlight either their workplace or own homes. Below, as shorthand, we sometimes refer to them as 'experts' if we consider their professional knowledge has influenced their personal actions and circumstances. Fourteen other participants were 'householders' building or already occupying houses constructed of timber, recycled materials, straw bale, and rammed earth - material choices consistent with principles of simple living as applied to housing design (Alexander \& McLeod, 2014; Alexander et al., 2012). Four houses were off-grid in rural areas within driving distance of Hobart. 
Some householders had experience of alternative social and legal housing arrangements such as co-housing and intentional communities. Some were at planning stage and seeking permissions to act; others were or had recently finished building or retrofitting; and still others had finished their build or retrofit years before. All made lifestyle choices consistent with voluntary simplicity; for example, by admitting they preferred to make and repair items rather than buy them; maintained vegetable gardens; and reduced waste by recycling, composting, and mindful purchasing. All but one interview took place in homes, settings ideal for witnessing the physical manifestations of their housing philosophies.

Nine expert participants had retrofitted; lived in, built, or planned to build their own homes with simplicity attributes (such as below average footprint area); or they had memories of, or aspirations for such a lifestyle. Retrofits were the most common among them and least common among householders, which is not to say that people expressing voluntary simplicity values do not retrofit. As such, there were several instances where experts expressed thoughts about simple living as it applied to their own homes and lifestyle choices. In other words, at the time of interview, those participants might not have been engaged in housing provision tasks informed by voluntary simplicity principles, but they had been, and their perspectives were invaluable given the small number of participants in the study, overall.

Interviews were semi-structured, conversational, and inductive (Mason, 2002). Conversations with participants from both groups centred on personal life stories; values and beliefs related to money, material, social justice, environment, and housing; perspectives on voluntary simplicity; and experiences of housing provision. After participants had reviewed and returned their transcripts, we used open coding to analyse the data and search for emergent ideas, opinions, attributes, and experiences to then characterize ideas about voluntary simplicity. From those codes emerged broader categories and subcategories, analysed cross-sectionally and condensed into overarching themes.

\section{Voluntary simplicity and housing provision processes}

The second suggestion that concerns us is this: we think a modest empirical case study may help address gaps in understanding about people's aspirations, pathways, and choices when dealing with housing provision processes.

Below, we consider the experiences our participants had when applying the practical philosophy of voluntary simplicity to housing provision processes and we draw on interviews with them to consider housing provision in terms of preparation, purchase, design, and permissions and implementation processes. Those four processes may appear linear. Yet, recurring themes emerged from our analysis and iterative references to our theoretical framework (Figure 1) and suggest the processes are messily characterized by contradictions and compromises.

\section{General observations}

Householders' homes were small by today's standards: at 100-150 square metres, they had $25-50 \%$ less floor area than most new Tasmanian homes. Householders preferred 
new materials simultaneously non-toxic, natural, and ethically and/or locally sourced, and sought recycled, reclaimed, and second-hand materials and furnishings. Reduced footprints and materials selection suggest a caring approach to this infrastructure and its relationship to other parts of the biosphere and social and economic domains.

Typically, interior layouts were open-plan designs for overlapping uses, and there were few spare or single-use spaces. Houses centred on generously sized social spaces connected to food preparation areas; again, this prioritization hints at the importance of community and the importance of connection as part of caring infrastructures. Where householders could connect to the grid they did, and augmented supplies of mains electricity and piped water with solar panels and rainwater tanks.

Urban participants valued physical proximity to work and social connections, including opportunities to avoid driving and access cultural and other amenities. Rural participants valued privacy, access to nature, home food production, and freedom from urban constraints. These groups typify two aspects of a debate about which settlement patterns and behaviours best support simple living: high-density urban living or partly self-sufficient rural living? Their choices to foster simplicity in one setting or another yielded unexpected or ongoing complications related to transport, access, and financial burden.

Most were owner-builders, but all engaged in parts of some building process or other, retrofitting included. Some cited savings for this hands-on approach; others wanted to learn new skills or craft a home for themselves. Many said deep philosophical purpose and keen sense of stewardship or care underpinned the expenditure of energy and time. Many valued the aesthetic elements of shaping a home and garden and spoke warmly about creativity and self-expression, which contrasts with their experiences of dealing with housing and planning policies. Several delighted in having easy, unmediated access to nature and more space than expected. One told us, 'it's nice to have everything here and be independent ... Walking out onto the deck and looking into the bush, there's an instant sense of freedom ... I'm aware it is a luxury ... not possible for everyone' (Householder 1, owner-built straw bale home, resident in Kingborough LGA). Such observations suggest both an appreciation of the infrastructure's capacity to help them care for their environs and exercise gratitude.

Such observations are striking considering that luxury means 'a state of great comfort or elegance, especially when involving great expense' (Oxford University Press, 2017). These dwellings might not be anywhere near luxurious by the standards applied to housing by Australia's financial elite, yet this phrase generates insights about the relativities of housing access, proximity to nature, and basic needs in challenging times.

\section{Preparation}

Preparing to build or retrofit presented the first in a series of contradictions and compromises to voluntary simplicity. One of our most powerful findings was the difference that knowledge and preparation make to householders' experiences and housing outcomes. We learned that political cycles and constant changes to systems may actively discourage a move from ideation to action. For example, amendments 
to legislation, policy, and regulation often affect the instruments that enable homebuyers to prepare to provide for their housing, among them grants, housing markets, or building codes - which often require that people act quickly. In this light, expert participants spoke about limited levels of consumer awareness about and preparedness to deal with purchasing and development control systems:

[Householders] really, really need to do their homework, and they're the only ones that can do it. Real estate won't do it; Council won't offer it to them on a platter ... All they have to do is ask. They don't even have to know what to ask ... This is where [Council] ... needs to get the message out to the ... community ... it's obvious to me - and obviously not obvious to other people - that if you've got a bush block [you have to prepare for] constraints. (Expert 9, Council planner, resident in Kingborough LGA)

Other householders also said that preparation could be lacking but, for example, even had one couple been prepared, their work would be stymied by subsequent changes to bushfire hazard management regulations, the advent of which restricted their choice of building materials:

[It was] a massive disappointment (and could have been a deal breaker when we bought the land) ... [that] we couldn't build what we wanted to build. [It] may have been because we didn't research enough ... But we weren't clear about [the regulations] at the time of purchase. (Householders $3 \mathrm{a}$ and $3 \mathrm{~b}$, rammed earth house, resident in Hobart LGA)

Householders found it difficult to obtain clear and timely preparatory information, especially in relation to development control forms and requirements. Some wanted a simple checklist of things to do, yet experts suggested that each project is distinct enough that even a modest universal checklist could be misleading.

Most householders were also attempting to enact simplicity values by making provision choices outside the norm for Tasmanian builds and could not assume clear pathways to approval. Systems guidance is important here, and those who worked with empathetic and transparent professionals seemed to fare best; in our reading of this situation, infrastructures of care arise from caring collaborations. Built environment professionals suggested householders should consult with them early on for guidance about preparing the ground for housing provision choices, particularly given the complexities of the digital platforms often used at this stage. They also acknowledged that digitization makes gathering information increasingly impersonal, and means some householders cannot or do not then ask, 'what else should I know about?'

Householders organized in advance with time, money, and paperwork expressed a higher level of satisfaction dealing with housing processes than those who were not. Universally, however, uncertainty and change fostered anxiety during preparation and subsequent phases, and relief was clear when work was finished: 'I could do it all again because [I would] be more confident, but I wouldn't want to for a long time' (Householder 6, straw bale new build, resident in Tasman LGA).

\section{Purchase}

Purchasing was a contradictory process requiring various compromises as people sought to enact simplicity values especially because, given recent increases in house 
prices in Tasmania relative to income, many householders required bank loans necessitating direct engagement with exactly the type of complex system they wished to avoid. Householders privileged time over money, many having moved from fullto part-time employment, and finances were philosophically and practically important for them because any additional downward shift their financial status equated with a commensurate loss of control to choose to live simply.

There was stark difference between those who bought homes before or in the mid2000s and those who did so after the recent housing market surge. Householders in the first category felt lucky they entered the market when they did. Yet, they did not speak about housing affordability for the next generation; rather, they encouraged them to avoid debt:

[I] came to Tasmania with about $\$ 60,000$. Land was cheap; I bought 15 acres in cash for $\$ 15,000$, and I still had $\$ 30,000$ left ... Your generation is just being forced into this huge debt ... And it's even more necessary for you to simplify and think about how much debt you're really willing to take on. Eventually, you really are supposed to pay it back ... We seem to think that it's okay to pay $\$ 300,000$ for a house, when it's as essential as eating. (Householder 8, straw bale new build, resident in Sorell LGA)

Some householders thought the system too large and pervasive to influence. They struggled to make trade-offs between voluntary simplicity values and methods to gain financial access to housing. Compromises on location caused angst. Those who purchased existing homes in urban areas valued proximity to employment, services, and social networks, but had higher purchasing prices and environmentally underperforming housing stock. Those who purchased in rural areas valued access to nature and the flexibility larger allotments gave, and many were building new houses, and could be discerning about orientation, materials, and design. But they grappled with having to clear vegetation to meet bushfire requirements and drive hours each day to access appropriate employment and varied services, pointing to other complexities in how, collectively, thought might be given to how infrastructures of care are created and experienced.

Debt was again central to thinking about trade-offs. Householders were debt-averse, wanting to live within their means, distrusting the financial sector, wanting their financial and personal freedom, and being uncertain about their ability to meet mortgage payments if personal circumstances changed:

For me to buy a property and a house, I'd be looking at ... a lifetime of debt ... I'd be signing up to have a job ... for the rest of my life ... [But yurts] are places where people ... [don't] have to get into masses of debt to live. That's ... the philosophy behind it. (Householder 10, yurt, resident in Huon Valley LGA)

One of the ideas is to keep debt low. [I've] been working full time for four years ... [We have] tried to pay as we go [and] haven't taken out a second loan ... [It's] really hard to get money from the bank once you start building because they see you as a risk. (Householder 5, straw bale new build, resident in Kingborough LGA)

Participants said debt led to other contradictions. Bankers could decide whether to issue loans to people with non-traditional working arrangements or eccentric house designs, and valuers could determine financing. 
If you end up maxing out your loan capacity ... you've borrowed to do the right thing by the environment or the community, and ... all that money ... goes to the bank ... If you spend [the loan] on a huge solar array and back-up batteries ... that money with interest is then going back to the bank ... Trying to do the good thing, [but] not thinking about where your money ... [ends] up: it's kind of a big deal. (Householder 4, timber clad retrofit, resident in Clarence LGA)

Thus, the relationship with debt shaped the financial resources available for other aspects of housing provision, affected life choices years before and after the purchase or building process, and influenced behaviours and capacities to live simply.

\section{Design}

Householders' relationship with housing design was personal and specific. Although values about function and aesthetics apply to any type of homeowner or dweller, these householders' were concerned to reduce environmental impacts, demonstrate a personal sense of built and natural beauty, foster a nourishing social life by creating inviting common spaces, and make personal contributions to house design by integrating personal artefacts or found objects. In short, in our reading, they wanted to create infrastructures in which care - of self, other, and Earth - was relatively easy.

Experts provided the most direct thinking about simplicity and design attributes: design for a small footprint and be mindful about site selection. And householders and experts alike favoured small homes to save costs and be ethically consistent. In the words of an energy efficiency researcher and assessor based in Hobart, 'to live simply, the first principle should be that small is better' (Expert 12).

Yet for householders, it was challenging to match desire with financial, regulatory, and site constraints. One said, 'there are weird things you'd never think of. It's hard to know all the rules because you need to be across building, plumbing, electrical, soil ... Finding those resources ... is difficult' (Householder 7, straw bale new build, resident in Kingborough LGA). So, for example, cladding that met bushfire regulations could be costly and difficult to source. Building regulations could preclude the use of non-compliant second-hand materials. Getting clearance for onsite greywater management and composting toilets often saw householders educating council staff and others more than expected.

Householders found that busy or disinterested council staff were sometimes more likely to engage with them once an expert was involved - and this observation harks back to an earlier one about the need for caring collaborations (including those set up to bring 'novices' along). One development control planner admitted it was easier working with experienced, known professionals than with owner-builders unaware of the challenges to provision choices posed by materials or systems they wanted to use. Those working in the building industry knew of this pressure on householders to use experts and several responded empathetically:

For anyone who does what I do, there's a responsibility to provide some sort of pastoral care. The whole process is difficult and stressful. I have always been slightly worried that people would finish up with something they don't want and have spent their life savings on. (Expert 8, building designer, resident in Hobart LGA) 
Choices related to design innovation and purchasing were also challenging. Harvey (2014, p. 43) explains that housing ... is captive to externality effects since investment or disinvestment in one house in a neighbourhood has an effect (either positive or negative) on the value of houses in the immediate vicinity'. Zoning, setback, minimum footprint size, and overlooking exemplify planning interventions meant to cope with these externalities.

\section{Permissions and implementation}

Participants were voluble in responding to questions about the permissions and implementation procedures that underpin housing provision and that unsettle or detract from their housing aspirations, voluntary simplicity included; this, too, underscores the persistent challenge of creating caring and collaborative systems to produce infrastructures of care and highlights the gaps between what seems to be widely wanted and what is practiced in the day-to-day 'grind' of bureaucratic engagement.

Once householders had made their initial preparations, secured a house and/or lot, and settled on their design, other contradictions and compromises typified their planning and building applications to relevant local government authorities. As with processes to secure financing, when planning and building householders needed to interact with others in a system that was often opaque, and that sometimes meant moving away from their desire to enact voluntary simplicity values in and by dwelling.

In Tasmania, housing provision involves proponents securing several council approvals before commencing and finalizing work. Our interviews focused on two: planning via municipal planning schemes, and building - which responds to Australia's National Construction Code via state legislation. Householders and experts viewed some level of regulation as necessary but said it felt as if one was guilty until proven innocent. Householders viewed the approvals process as overly and overwhelmingly administrative and procedural. Several experts attributed over-regulation to single examples of negative cases that sparked regulatory changes, resulted in blunt instruments, and discouraged innovation, social change, and simple approaches. Some of them felt that increasing regulation threatened planning as urban design and artistry: 'We're dumbing it down to such an extent that we've lost all opportunity for education, understanding, dialogue, narrative; all that's been lost' (Expert 19, planning consultant, resident in Hobart LGA).

Householders and experts thought over-regulation demonstrated diminished trust and personal responsibility at a societal level. Several felt a keen sense of duty to build high-quality houses and householders lamented having to pay for assessments to demonstrate diligence they said they would have shown in any case. There was widespread support for regulations related to environmental impacts and energy efficiency, but, given that some assessment reports cost $\$ 2000$ or more, were distrustful and cynical about the ways in which regulations buttressed commercial ventures.

Over-regulation can, of course, lead to complex decision chains requiring still more expertise. Householder 3 has a professionally built rammed earth house in Hobart LGA and had a dispute with council over bushfire regulations; these required vegetation clearance beyond the property boundary into a council reserve. 'At the Tribunal, I don't think anyone knew what was going on except for the council lawyer 
and the planning consultant; they were basically just talking to each other'. When asked if they could have managed without representation, Householder 3 replied,

no chance ... We didn't understand what we were getting into. We wouldn't have been able to do it without the consultant ... There would be so many environmental laws we wouldn't have had a clue about. It would be intimidating dealing with a council lawyer. We wouldn't have known where to start.

Approvals processes seemed like roadblocks, and participants thought development control regulations were inaccessible for most laypeople and even some experts. Householders were frustrated with complexity and ambiguity about what was required of them. Frequent changes to legislation sometimes meant having to build quickly.

Bespoke checklists of requirements were absent - noting criticisms of them described above. Householders had to explain themselves multiple times to different council officers and required much expertise or tacit knowledge to understand what was expected of them. The overall cost of the approvals process was also high given the volume of compliance work required of them.

Finally, householders and experts diverged on the meaning of suitable locations for housing. Several householders favoured rural areas for the affective experience of living close to nature and because they could better afford the purchase. Experts overwhelmingly supported infill development, retrofitted housing stock, and limited fringe development requiring car use. Almost always, the rationale was that there would be no land left to build on, one forecasting this scenario: 'we had that luxury, and we squandered it' (Expert 14, planning lawyer, resident in Hobart LGA).

Once permissions are secured, the implementation stage is also filled with contradictions and compromises. For example, one-third of the total waste stream in Tasmania results from construction and demolition. Waste management practices are profoundly affected by procurement culture and behaviours on the part of clients, architects, designers, planners, engineers, site operatives, contractors, and subcontractors.

Not surprisingly, then, the materials supply chain was subject to further trade-offs by householders. It is difficult to obtain ethically or sustainably sourced building materials in Tasmania, and some householders were averse to using Tasmanian timber because of their views on forest industry practices. This position required that they purchase responsibly produced materials shipped onshore using fossil fuels, which conflicted with simple values to consume consuming locally and reduce emissions. Prices could be exorbitant.

Experts corroborated the existence of such conundrums:

Finding ethically sourced materials is notoriously ... difficult ... [so too being] sure of the lineage of the materials that you're getting. Green-washing is rife ... You need to ... have an expert eye ... Typical householders [work with] ... what they're told by manufacturers ... [I've often had people] come and say they're using certain material because it's green. I have to tell them, no, it's probably not. (Expert 12, energy efficiency assessor and researcher, resident in Hobart LGA)

These gaps in knowledge about lineage and pricing caused several householders to compromise on voluntary simplicity values as the housing process progressed:

[We're] having to go with more concrete and steel and new materials, which we hadn't wanted ... You want to [be] a point of difference and a model of simplicity ... no one 
is envious of the situation we're currently in ... Every little thing is quite complex when you're building. (Householder 7, straw bale new build, resident in Kingborough LGA)

Finally, a central challenge was summarized by one of the householders: 'Things that might be seen as making life simple can be complex, because of how society can be structured ... in terms of expectations ... norms and ... the bureaucracy'. Participants most able to live simply were adept at working the system, or made serious trade-offs to avoid it, or were simply lucky, and we turn to these in the next section on the understanding that these tendencies also characterized the three other elements of the provision process we have considered.

\section{Discussion and conclusions}

Our findings suggest, first, that some householders could draw on or had developed high-level management capacities: organizational skills, resourcefulness, attention to detail, networking skills, objectivity, persistence, the ability to see the big picture and plan, and a degree of extroversion (whether they were extroverted or not). These attributes meant they could investigate and select from various strategies and tactics to avoid costly delays or bureaucratic requirements. They selected blocks of land or houses needing fewer inputs to match their voluntary simplicity ideals. They held experts accountable and asked targeted questions.

Second, some sacrificed the security, comfort, or potential longevity of their houses to live simply - they took risks. Examples include building in areas prone to bushfire or with less durable materials. They also made less-tangible sacrifices such as assuming debt or living far enough from services to necessitate driving.

Third, several appeared to have developed financial savvy and purchased their homes or blocks when prices were lower and planning and building regulations less extensive, enabling them to pay off debts sooner or build their houses more easily, creatively, or over longer periods of time. Some originally came from positions of privilege, in terms of access to education and lucrative employment. Some moved to Tasmania, bringing savings from higher-paying jobs or the proceeds of house-sale in a more expensive area.

Beyond management skills, risk appetite, and financial nous we think it useful to speculate about whether voluntary simplicity might be a compelling response to contemporary challenges if more ready access were available to time, financial resources, expertise, and healthful places and appropriate materials. We think more work on such matters is certainly warranted, so the following comments are intended to invite further conversation.

Those with time were able to live simply by building houses over longer periods, investigating options thoroughly, learning new skills, and building for themselves. Access to time meant needing to pay for fewer services that, with practice, could be done without expert input. Lack of time is a common justification for inaction or decisions based on convenience or comfort that necessitate consumption. Having time increases capacity and self-sufficiency to satisfy basic needs and to feel fulfilled, be thoughtful about values, and live actively in the world because of such reflection. 
Those participants who were more affluent could afford houses or blocks that met more criteria for voluntary simplicity: flat, north-facing blocks, using high-quality and highly ecologically friendly materials, at locations close to services and amenities. Affluent participants could source top-quality services to avoid purchasing suboptimal blocks or designing sub-optimal houses, thus saving time. Yet conflicting views about money highlighted gaps between theory and practice. None of the householders would have been able to afford the types of houses that experts promoted if one accounts for their contexts and values - especially those related to work and finances. Although experts suggested building smaller houses that are less expensive, they were adamant that it is better to live closer to urban centres to reduce transport emissions and the need to clear greenfield sites. To meet this requirement, householders would need to be willing to take on substantial mortgages, buy-in lower-income neighbourhoods that tend to have lower-quality housing stock (thus involving greater financial inputs to meet values held by householders), work longer hours or in highpaying jobs, or rent long-term - options none of the householders preferred.

Clearly, these insights speak back to the literature on housing and on voluntary simplicity as well as that emerging in relation to infrastructures of care. Thus, to live a simple life involves a high degree of self-awareness and self-restraint, and an intimate knowledge of how social, environmental, and housing systems function - of how housing pathways and choices are shaped (Clapham, 2002, 2005) and how aspirations are formed (Preece et al., 2020). An ability to take a 'helicopter view' of overlapping systems of governance, finance, culture, and environment seems necessary if people are to feel empowered to act and to care, even when overwhelmed (Power \& Mee, 2019). Access to expertise and knowledge held by householders themselves or by people in their networks saves time and money and enables them to work effectively with experts because they know which questions to ask. There are fewer 'unknown unknowns' and 'knowledge is power'.

Access to healthy places likewise results in savings. Properties that meet voluntary simplicity 'specifications' already give householders a head-start. Almost as helpful is the option, leveraged by several householders in this study, to live on their blocks while building and save in time and rent and transport costs. Access to appropriate materials makes a lesser but important difference. Some householders were shrewd about obtaining second-hand materials that meet building standards, for example.

Finally, many participants made trade-offs to obtain more of one resource money for time, time for knowledge, and so on - but obstacles remained. Many also expressed a willingness to 'step up' to the task but still felt that 'the system' was against them: 'it's a game you can't win' (Householder 10, yurt, resident in Kingborough LGA). The need or willingness to make these trade-offs also led to questions about voluntary simplicity as a complex philosophical practice. Householders and experts alike engaged in loose quantifications and contradictory calculations about making socially caring, economically just, or ecologically friendly or unfriendly decisions, with hopes of having net-positive impacts. It quickly became apparent that they often made compromises, demonstrating that sustainability, like voluntary simplicity, is subjectively constructed as people give meaning to both the word and the actions required of it (Black \& Cherrier, 2010). 
In closing, we suggest that voluntary simplicity may not be enough to neutralize the social and environmental crises we face, but participants in this study show that it is worth trying. We think this outcome points to the need for more in the way of scholarship at the interface between housing studies and studies of social values and aspirations such as voluntary simplicity. We also advocate more theoretical and empirical work to delineate the relationships that exist among values and aspirations, housing pathways and choices, housing provision processes and their outputs and outcomes, and the infrastructures of care that can emerge.

\section{Disclosure statement}

No potential conflict of interest was reported by the author(s).

\section{Notes on contributors}

Marisa McArthur is a PhD Candidate in the Discipline of Geography and Spatial Sciences. The work reported here is drawn in part from her Masters of Environmental Planning, for which she was awarded the Mike Shield Award recognising the student graduating in the calendar year of the award with the best overall academic performance.

Elaine Stratford is Professor of Geography in the Discipline of Geography and Spatial Sciences.

\section{ORCID}

Elaine Stratford (D) http://orcid.org/0000-0001-6273-493X

\section{References}

Alexander, C., Bruun, M. H. \& Koch, I. (2018) Political economy comes home: On the moral economies of housing, Critique of Anthropology, 38, pp. 121-139.

Alexander, S. (2011) Property beyond growth: toward a politics of voluntary simplicity. Unpublished PhD thesis, University of Melbourne, Melbourne.

Alexander, S. (2012a) Degrowth Implies Voluntary Simplicity: Overcoming Barriers to Sustainable Consumption. Simplicity Institute Report 12b. Available at http://simplicityinstitute.org/wpcontent/uploads/2011/04/OvercomingBarrierstoSustainableConsumptionReport-12b.pdf (accessed 29 July 2018).

Alexander, S. (2012b) The voluntary simplicity movement: Reimagining the good life beyond consumer culture. Available at SSRN: https://ssrn.com/abstract=1970056 or http://dx.doi. org/10.2139/ssrn.1970056 (accessed 29 July 2018).

Alexander, S. \& McLeod, A. (2014) Simple Living in History: Pioneers of the Deep Future (Melbourne: Simplicity Institute Publishing).

Alexander, S. \& Ussher, S. (2012) The voluntary simplicity movement: A multi-national survey analysis in theoretical context, Journal of Consumer Culture, 12, pp. 66-86.

Alexander, S., Trainer, T. \& Ussher, S. (2012) The Simpler Way: A Practical Guide to Living More with Less. Simplicity Institute Report 12a. Available at http://simplicityinstitute.org/ wp-content/uploads/2011/04/The-Simpler-Way-Report-12a.pdf (accessed 29 July 2018).

Australian Bureau of Statistics (2005) Australian home size is growing. Available at http://www.abs. gov.au/AUSSTATS/abs@.nsf/Previousproducts/1301.0Feature\%20Article262005. (accessed 29 July 2018). 
Australian Bureau of Statistics (2011) Moving house. Available at http://www.abs.gov.au/ AUSSTATS/abs@.nsf/Lookup/4102.0Main \pm Features30Dec \pm 2010 (accessed 29 July 2018).

Australian Bureau of Statistics (2013) Feature article: Average floor area of new residential dwellings. Available at http://www.abs.gov.au/AUSSTATS/abs@.nsf/Previousproducts/8752. 0Feature\%20Article1Jun\%202013 (accessed 28 June 2018).

Australian Bureau of Statistics (2017a) 2016 Census Community Profiles: Tasmania - Time Series Profile. Available at http://www.censusdata.abs.gov.au/census_services/getproduct/ census/2016/communityprofile/6?opendocument (accessed 28 June 2018).

Australian Bureau of Statistics (2017b) Census: Younger Australians more likely to make a move. Available at http://www.abs.gov.au/ausstats/abs@.nsf/mediareleasesbyReleaseDate/ 64EEC2403E851326CA2581BF0036648E?OpenDocument (accessed 28 June 2018).

Australian Bureau of Statistics (2019a) 8752.0 - Building Activity, Australia, December 2019. Characteristics of New Residential Dwellings - A 15 Year Summary. Available at https://www. abs.gov.au/AUSSTATS/abs@.nsf/featurearticlesbyCatalogue/CD409379BD228908CA258321000B96 CA?OpenDocument (accessed 29 July 2019).

Australian Bureau of Statistics (2019b) 6416.0 - Residential Property Price Indexes: Eight Capital Cities, March 2019. Available at https://www.abs.gov.au/ausstats/abs@.nsf/mf/6416 (accessed 29 July 2019).

Black, I. \& Cherrier, H. (2010) Anti-consumption as part of living a sustainable lifestyle: Daily practices, contextual motivations and subjective values, Journal of Consumer Behaviour, 9, pp. 437-453.

Bhatti, M. (1993) From consumers to prosumers: Housing for a sustainable future, Housing Studies, 8, pp. 98-108.

Brown, T. \& Bhatti, M. (2003) Whatever happened to 'housing and the environment'? Housing Studies, 18, pp. 505-515.

Chhetri, P., Khan, A., Stimson, R. \& Western, J. (2009) Why bother to "downshift"? The characteristics and satisfaction of downshifters in the Brisbane-South East Queensland Region, Australia, Journal of Population Research, 26, pp. 51-72.

Clapham, D. (2002) Housing pathways: A postmodern analytical framework. Housing Theory and Society, 19(2), pp. 57-68.

Clapham, D. (2005) The Meaning of Housing: A Pathways Approach (Bristol: Bristol University Press).

CommSec (2017) Economic insights: Australia home size hits 20-year low. Available at https:// www.commsec.com.au/content/dam/EN/ResearchNews/ECOReport.20.11.17_Biggest\%20homes_ size-fall.pdf (accessed 28 June 2018).

Crabtree, L. \& Hes, D. (2009) Sustainability uptake in housing in metropolitan Australia: An institutional problem, not a technological one, Housing Studies, 24, pp. 203-224.

Crabtree, L. (2018) Self-organised housing in Australia: Housing diversity in an age of market heat, International Journal of Housing Policy, 18, pp. 15-34.

Craig-Lees, M. \& Hill, C. (2002) Understanding voluntary simplifiers, Psychology and Marketing, 19, pp. 187-210.

Eccleston, R., Warren, N., Verdouw, J., Flanagan, K. \& Eslake, S. (2018a) A Blueprint for Improving Housing Outcomes in Tasmania - Insight Three (Hobart: Institute for the Study of Social Change, College of Arts, Law and Education, University of Tasmania). Available at http://www.utas.edu.au/data/assets/pdf_file/0009/1074609/Insight-Three-Housing-Web-Version.pdf (accessed 29 July 2018).

Eccleston, R., Denny, L., Flanagan, K., Jacobs, K. \& Glaetzer, S. (2018b) Tasmanian Housing Summit Directions Paper (Hobart: Institute for the Study of Social Change, University of Tasmania). Available at https://eprints.utas.edu.au/27327/1/Ecclestonal2018-HousingSummitDirections.pdf

Elgin, D. (1981) Voluntary Simplicity: Toward a Way of Life that is Outwardly Simple, Inwardly Rich (New York: William Morrow).

Elgin, D. (2010) Voluntary Simplicity (New York: Harper). 
Eslake, S. (2016) Tasmania Report 2016 for the Tasmanian Chamber of Commerce and Industry. Available at http://www.tcci.com.au/Events/Past-Events/Tasmania-Report-2016 (accessed 28 June 2018).

Evans, D. (2011) Thrifty, green or frugal: Reflections on sustainable consumption in a changing economic climate, Geoforum, 42, pp. 550-557.

Etzioni, A. (1998) Voluntary simplicity: Characterization, select psychological implications, and societal consequences, Journal of Economic Psychology, 19, pp. 619-643.

Field, M. (2015) Planning for Voluntary Simplicity: Housing Frameworks and the Complexities of the Simple Life in South-Eastern Tasmania (Hobart: Discipline of Geography and Spatial Science, School of Land and Food). Unpublished MEnvPlg dissertation.

Gleeson, B. (2006) Australian Heartlands (Sydney: Allen \& Unwin).

Gleeson, B. (2015) The Urban Condition (Abingdon/New York: Routledge).

Greenop, K. (2017) Understanding housing precarity: More than access to a shelter, housing is essential for a decent life, Global Discourse, 7, pp. 489-495.

Gregg, R. (1936) The Value of Voluntary Simplicity. Pendle Hill Essays (Wallingford, PA: Quaker Center for Religious and Social Study). Available at http://www.soilandhealth.org/ 03sov/0304spiritpsych/030409simplicity/SimplicityFrame.html (accessed 29 July 2018).

Gurran, N. (2011) Australian Urban Land Use Planning (Sydney: University of Sydney Press).

Harvey, D. (2014) Seventeen Contradictions and the End of Capitalism (London: Profile Books).

Kemeny, J. (1992) Housing and Social Theory (London: Routledge).

Kollmus, A. \& Agyeman, J. (2002) Mind the gap: Why do people act environmentally and what are the barriers to pro-environmental behavior? Environmental Education Research, 8, pp. 239-260.

Legacy, C., Cook, N., Rogers, D. \& Ruming, K. (2018) Planning the post-political city: Exploring public participation in the contemporary Australian City [Introduction to Special Section], Geographical Research, 56, pp. 176-180.

Leonard-Barton, D. (1981) Voluntary simplicity lifestyles and energy conservation, Journal of Consumer Research, 8, pp. 243-252.

MacDonald, H. (2018) Has planning been de-democratised in Sydney? Geographical Research, 56, pp. 230-240.

Mason, J. (2002) Qualitative Researching, 2nd ed. (Thousand Oaks, CA/London/New Delhi: Sage).

McDonald, S., Oates, C., Young, C. \& Hwang, K. (2006) Toward sustainable consumption: Researching voluntary simplifiers, Psychology and Marketing, 23, pp. 515-534.

McGee, C. (2013) Welcome to your home, in: Your Home: Australia's Guide to Environmentally Sustainable Homes, pp. v-vii (Canberra: Australian Government Department of Industry).

McGinnis, L., Frendle, A. \& Gentry, J. (2013) The simple man: The consumption behavior of the principled life, Journal of Consumer Behaviour, 12, pp. 70-80.

Moore, T., Strengers, Y., \& Maller, C. (2016) Utilising mixed methods research to inform lowcarbon social housing performance policy. Urban Policy and Research, 34(3), pp. 240-255.

Opit, S., Witten, K., \& Kearns, R. (2020) Housing pathways, aspirations and preferences of young adults within increasing urban density. Housing Studies, 35(1), pp. 123-142.

Oxford University Press (2017) Oxford Dictionaries. Available at http://www.oxforddictionaries. $\mathrm{com} /$ (accessed 28 June 2018).

Pickerill, J. (2017) Critically interrogating eco-homes, International Journal of Urban and Regional Research, 41, pp. 353-365.

Power, E. R. \& Mee, K. J. (2019) Housing: An infrastructure of care, Housing Studies, pp. 1-22. doi: $10.1080 / 02673037.2019 .1612038$

Preece, J., Crawford, J., McKee, K., Flint, J., \& Robinson, D. (2020) Understanding changing housing aspirations: A review of the evidence. Housing Studies, 35(1), pp. 87-106.

Read, R., Alexander, S. \& Garrett, J. (2018) Voluntary simplicity strongly backed by all three main normative-ethical traditions, Ethical Perspectives, 25, pp. 87-116. 
Rees, W. (2010) The human nature of unsustainability, in: R. Heinberg \& D. Lerch (Eds) The Post-Carbon Reader, pp. 1-7 (Healdsburg, CA: Watershed Media).

Rees, W. (2012) Cities as dissipative structures: Global change and the vulnerability of urban civilization, in: M. Weinstein \& R. Turner (Eds) Sustainability Science, pp. 247-273 (New York: Springer).

Reynolds, H. (2012) A History of Tasmania (Cambridge: Cambridge University Press).

Sandlin, J. \& Walther, C. (2009) Complicated simplicity: Moral identity formation and social movement learning in the voluntary simplicity movement, Adult Education Quarterly, 59, pp. 298-317.

Schifferes, J. \& Shafique, A. (2018) Housing. Real estate, RSA Journal, 5574, pp. 11-15.

Standing, G. (2011) The Precariat: The New Dangerous Class (New York: Bloomsbury).

Steele, W. (2009) Australian urban planners: Hybrid roles and professional dilemmas? Urban Policy and Research, 27, pp. 189-203.

Stone, W., Reynolds, M. \& Burke, T. (2017) Home ownership remains strong in Australia but it masks other problems: Census data. The Conversation, 27 June. Available at https:// theconversation.com/home-ownership-remains-strong-in-australia-but-it-masks-other-problemscensus-data-80068 (accessed 29 July 2018).

Stratford, E. (2003) Flows and boundaries: Small island discourses and the challenge of sustainability, community and local environments. Local Environment, 8(5), pp. 495-99.

Stratford, E. (2006a) Isolation as disability and resource: Considering sub-national island status in the constitution of the 'New Tasmania'. The Round Table: Commonwealth Journal of International Affairs, 95(386), pp. 575-588.

Stratford, E. (2006b) Technologies of agency and performance: Tasmania Together and the constitution of harmonious island identity. Geoforum, 37(2), pp. 273-286.

Stratford, E. (2008) Islandness and struggles over development: A Tasmanian case study. Political Geography, 27(2), pp. 160-175.

Stratford, E., \& Bradshaw, M. (2016) Qualitative research design and rigour, in: I. Hay (Ed) Qualitative Research Methods in Human Geography, 4th ed., pp. 117-129 (Ontario, Canada: Oxford University Press).

Timms, P. (2009) In Search of Hobart (Sydney: University of New South Wales Press).

Wright, E. O. (2013) Transforming capitalism through real utopias, American Sociological Review, 78, pp. 1-25.

Zamwel, E., Sasson-Levy, O. \& Ben-Porat, G. (2014) Voluntary simplifiers as political consumers: Individuals practicing politics through reduced consumption, Journal of Consumer Culture, 14, pp. 199-217. 